\title{
Two Anniversaries 75 Years of International Congresses of Phonetic Sciences and 50 Years of Phonetica
}

\author{
Some Epistemological Reflexions on the Theory and \\ Methodology of Phonetic Science
}

\section{The International Congresses of Phonetic Sciences and the Permanent Council for Their Organization}

In 1928, at the First International Congress of Linguists, de Groot proposed that an international periodical of Experimental Linguistics be started 'in order to further the cooperation of Experimental Phonetics, Experimental Psychology and Linguistics, for the study of Language'. He then presented the following explanatory memorandum:

Instrumental methods are of great importance in nearly every chapter of Linguistic Phonetics, but they need improvement. Neither the nature of speech-elements, which are semantic elements, nor the special requirements of Linguistics, are always sufficiently taken into account. We often meet a tendency to identify physiological or physical with psychical phenomena; the fact that speech elements have a (semantic) function, and that functional elements of speech are not identical with qualities of speech-form (such as variations in stress, melody, duration) and that their chief interest for the linguist ... lies in the fact that they are functioning elements, is often overlooked. The complex character of vibration and movement curves is not always sufficiently recognized as being the result of a number of tendencies, most of which aim at realizing a definite function of speech. As to the requirements of linguistics: the phonetician sometimes even confines the field of Experimental Phonetics to what is of no interest to the linguist at all; he frequently fails to draw from his results the conclusions which would be of interest to the linguist; his chief interest is often concentrated upon instruments and curves, instead of upon the elements and the functions of speech; more than once instruments are used where instrumental research is superfluous. The methods of Linguistic Phonetics are, of course, linguistic, i.e. semantic, i.e. in the first place psychological methods; the fact that the problems of Linguistic Phonetics are in the last resort not instrumental, or physiological, or physical problems, but semantic, i.e. psychological problems, is too often overlooked [de Groot, 1928].

The type of experimental phonetics de Groot had in mind was that practised at his time by such scholars as E.W. Scripture and G. Panconcelli-Calzia, who tried to replace 'subjective' linguistic phonetic categorization by 'objective' physiological, articulatory, and acoustic measurements, thus creating a dichotomy between the traditional analysis of language within the humanities and a new paradigm within natural science. De Groot's aim is clear: to overcome the development of this schism by getting Experimental Phonetics, Experimental Psychology and Linguistics together in the elucidation of sound and sense in speech communication, i.e. to integrate speech signal analysis into the investigation of function and meaning. Before his proposition to launch a journal in pursuit of this goal could be realized, an alternative platform, namely that of a scientific meeting came into being, which picked up on these ideas.

\begin{tabular}{ll}
\hline KARGER & @ 2007 S. Karger AG, Basel \\
$0031-8388 / 07 / 0643-0073$ \\
Fax +41 61 306 12 34 & $\$ 23.50 / 0$ \\
E-Mail karger@ karger.ch & Accessible online at: \\
www.karger.com & www.karger.com/pho
\end{tabular}


The Dutch Society of Phonetics, represented by the psychologist van Ginneken, the phonetician Louise Kaiser and the linguist de Groot planned a congress, to be held in Amsterdam in 1932, to which they invited not only experimental phoneticians but also the newly founded 'Internationale Arbeitsgemeinschaft für Phonologie' of the Prague Circle and 'all those who were interested in any aspect of speech sounds ....[to] meet and work together' [Fischer-Jørgensen, 1984]. This congress became the First International Congress of Phonetic Sciences.

At the end of this congress, its President van Ginneken proposed an international Permanent Council with representatives from the various phonetic sciences which had joined forces in Amsterdam. The task of this Permanent Council was the planning of another International Congress of Phonetic Sciences by designating its president and fixing the place where it was to be held. The following were proposed as members, accepted their nomination and were elected: the musicologist Bernet Kempers, The Hague, the statistician F. Bernstein, Göttingen, the 'Schallanalyse' expert F. Karg, Leipzig, the neurologist Eberhard Zwirner, Berlin, the psychiatrist E. Feuchtwanger, Munich, the linguists A. Sommerfelt, Oslo, and Marcel Cohen, Paris, the anthropologist Kleiweg de Zwaan, Amsterdam, the philosopher H.J. Pos, Amsterdam, the phoneticians R.H. Stetson, Ohio, Daniel Jones, London, Pierre Fouché, Paris, Louise Kaiser, Amsterdam, the phonologist Prince N. Trubetzkoy, Vienna, and the psychologist J. van Ginneken, Nijmegen as the President. So, the 1932 Congress was the beginning of a series of, latterly quadrennial, gatherings of speech scientists from around the world. This year's 16th Congress thus marks the 75th anniversary of its inauguration and of setting up a Permanent Council for the Organization of International Congresses of Phonetic Sciences.

\section{Phonetics and Phonology - Dichotomy and Integration}

The Amsterdam Congress was opened by a paper on comparative phonology of the languages of the world by Trubetzkoy [1932], followed by further contributions from the Prague Circle, and complemented, on the following days, in the spirit of the pluralistic concept of phonetic sciences, by papers on anatomical, physiological and articulatory aspects, including instrumental demonstrations, as well as on the psychology of speech. Among the contributions, we find a seminal paper by Eberhard Zwirner [1932] on the issue of the three-way relationship between socially and geographically normative units of language that evolve and change historically, on the one hand, and the perceptual estimation of parameters of sound impressions, on the other, and finally the measurement of physical and physiological properties of speech by numbers and units. The latter is the domain of science, specifically of experimental phonetics, the first of linguistics, specifically of phonology, and the second of psychology. The relationship between the three domains is one of allocation ('Zuordnung'), and Zwirner expounds this concept with reference to the three time categories 'quantity', 'estimation of sound duration', and 'temporal measurement in sound curves', be they physiological, articulatory or acoustic. For him the question is not as to how the linguistic or psychological differentiation between short and long sounds (e.g. vowels in German) can be replaced, modified or justified by objective measurement, as was advocated by experimental phonetics. The only sensible question that can be raised is what objective data are related to the linguistic differences and structures, and how the perceptual evaluation is related to the measurements of physical objects, on the one hand, and to 
linguistic (phonological) units on the other. This is not just a superficial union of the three areas of phonetic investigation, which had developed side by side, but an epistemological enquiry into how physical measurement and psychological assessment of speech behaviour can be linked to language categorization, considering that each originates in, and is defined by, a different universe of statements about communicating by sound. In this view, the objects of study - sound classes, sound perceptions, features of speech curves - are determined by the method, i.e. a set of conventions for conceptualizing each level. However, for the elucidation of speech communication, language categories are the prime concern, and everything else needs to be related to them. Thus, the objects of investigation in phonetics are to be the language categories established by communication research, more specifically linguistic units, such as the word, and the phoneme developed by the Prague Circle. For this new kind of phonetics, which puts the different fields of investigation into a relational network, with normative language entities at its centre, Zwirner proposed a new name: 'Phonometry' ('Phonometrie'). It was presented to the international scientific community for the first time in that paper at the First International Congress of Phonetic Sciences, and was later elaborated in his book Grundfragen der Phonometrie [Zwirner and Zwirner, 1936], published together with the mathematician Kurt Zwirner (no family relation). There, he set two further requirements for speech communication research: working with data from natural speech interaction and statistical analysis of the variability of measurements related to language categories.

This was a very modern approach to phonetics, too advanced at his time for the scientific world to grasp and follow as a new paradigm for doing research. The mainstream developed and elaborated the dichotomy of (experimental) phonetics and (linguistic) phonology, belonging to science and the humanities, respectively, and this philosophy of science view of phonetics as a bipartitioned field has persisted ever since. There have been various attempts to bridge the gap between the two subfields over the years, proposing interfaces between phonetics and phonology, but leaving the sciences - humanities dichotomy untouched and never reaching the standard of Zwirner's argumentation. In particular, concepts within the two fields have become reified as realities for speakers and hearers in the communication process, rather than being objects created by scientific conceptualization outside the ontological question. Phonemes become perceptual realities, acoustic parameters enter into categorical perception, and articulatory movements and their physiological antecedents code linguistic categories in speech production, which are justified post hoc by inferential statistics applied to physical measurements. This is quite a different epistemological perspective from the concept of allocation between the three phonetic levels, fostering the behaviouristic conviction that linguistic and perceptual categories can be soaked up from the data by simply observing and measuring them in great quantity.

A currently prevalent paradigm in speech research tries to bring the two fields of phonetics and phonology together again by taking phonology into the laboratory, thus filling given linguistic units with substance and letting measurements of substance parameters and their statistical significance decide on the existence of language categories, i.e. phonology is being turned into a science as well [Pierrehumbert et al., 2000]. In one sense, this is a return to the philosophy of science in Experimental Phonetics of the late 19th and early 20th century, in another it goes even further because, whereas Experimental Phonetics dissolved all linguistic units, replacing 
them by measurement numbers, there is now the inherent danger of assuming that the phonological categories are given to be validated through experimental analysis of physical properties.

This signal-based approach to linguistic units was no doubt triggered through research questions raised by engineers in speech technology, automatic speech recognition in particular. In that framework, where a research goal is the development of efficient communication systems of humans with machines or even between machines, the incoming speech signal needs to be decoded and attributed to linguistic units. However, in this case of a practical application of signal processing algorithms to speech detection and classification, the conventions of enquiry are different from the enquiry into human speech communication. What matters is a satisfactory performance of the recognition model, irrespective of the classification procedure applied. If statistical models work better they are preferred to cognitive linguistic models, and Jellinek's statement of 20 years ago that his recognition rate went up whenever he fired a linguist highlights this focus. But the linguists' aim is different: they want to explain how natural speech communication works and why things are they way they are. So they focus on different objects in their field of enquiry, although they can learn a great deal from ASR research for their own scientific questions. But in principle their approaches need to be different, and this difference should be acknowledged. The growing tendency in phonetic science to apply signal-based analysis blindly and without due regard to communicative function needs readjusting. I think, therefore, that the time has come to reflect again about future developments in theory and methodology of speech communication research. In doing this, we cannot help but also raise the question of publication standards, in view of the confusing abundance of papers churned out for the proceedings of the ever increasing number of speech science conferences.

\section{Shaping an International Periodical of Phonetic Science - Phonetica}

Before developing these thoughts further, let me pick up the thread of de Groot's proposal of a new journal of phonetics to mirror the kind of integrated framework he envisaged. At the time he made his proposal, there were national and domain-specific journals of phonetics, mostly with a checkered and short-lived publication history. Only Le Maître Phonétique of the Association Phonétique Intetnationale could boast a continuous tradition as an international journal, but it was restricted to the practical description of the sounds of languages. The Archives Néerlandaises de Phonétique Expérimentale, which published the Proceedings of the First International Congress of Phonetic Sciences in 1933, stopped appearing just as did Zeitschrift für Experimentalphonetik of the International Society of Experimental Phonetics, under the editorship of E.W. Scripture. G. Panconcelli-Calzia edited Vox, Mitteilungen aus dem Phonetischen Laboratorium der Hansischen Universität zu Hamburg; it was a continuation of Internationales Zentralblatt für Experimentelle Phonetik Vox, and also incorporated the tradition of W. Viëtor's Phonetische Studien: Zeitschrift für wissenschaftliche und praktische Phonetik after its publication was discontinued. Vox was thus the only journal of international standing at the time that also covered a broad area of phonetics.

In 1936, Eberhard Zwirner received the rights for this journal. His intention was to continue Vox as a comprehensive journal of phonetics under the name of Archiv für 
die gesamte Phonetik and to place it with the medical publisher S. Karger, still in Berlin at the time, who already published Archiv für experimentelle und klinische Phonetik. The publisher advised Zwirner to publish the journal in two sections, addressing the linguistic aspect in Archiv für vergleichende Phonetik and the medical aspect in Archiv für Sprach- und Stimmheilkunde und angewandte Phonetik. However, the political circumstances killed his plan: Zwirner was not allowed to start a scientific journal in a Jewish publishing firm. He needed to look for another publisher and also for another editor. Metten \& Co., Berlin, took on the publication of Archiv für die gesamte Phonetik and its two sections. In the linguistic section, the Africanist Diedrich Westermann, Berlin, became the chief scientific editor. The board was truly international and covered a wide range of fields, including E. Blancquaert, Ghent (the organizer of the Third International Congress of Phonetic Sciences in 1938), T. Chiba, Tokio, P. Fouché, Paris, O. Jespersen, Copenhagen, D. Jones, London, C.E. Parmenter, Chicago, F. Trendelenburg, Berlin. In the medical section, the board included D. Guthrie, Edinburgh, H. Gutzmann, Berlin, R. Janker, Bonn, F. Tarneaud, Paris, and F. Wethlo, Berlin. Publication began in 1937 in both sections, but ceased in 1943 due to the War.

So, de Groot's proposal had found its first realization, but, like the International Congress of Phonetic Sciences, was interrupted by World War II. The medical section of the Archiv started up again in 1947, under the editorship of Richard Luchsinger, Zürich, as Folia Phoniatrica with S. Karger, now in Basel, Switzerland. The linguistic section followed 10 years later as Phonetica under the roof of the same publishing house. We are proud that this year we can celebrate the 50th anniversary of the first international journal of phonetic science, which has its ultimate roots in the First International Congress of Phonetic Sciences 75 years ago, and which, in spite of the difficulties preceding its birth, has turned into a very healthy forum for speech communication research. In keeping with de Groot's memorandum and with the epistemological stand of Zwirner's phonometry, its goal has always been the theoretical and methodological discussion of the fundamental questions concerning the relationship between phonetics and phonology in the analysis of speech communication, and the presentation of empirical data within this framework. In addition to regular submissions of papers, the journal has published surveys of research areas, and has also solicited papers for thematic issues on various linguistic and communicative topics of great actuality. Since 1981, nine such volumes have appeared, uniting papers on: 'Temporal Aspects of Speech Production and Perception' (vol. 38, 1981), 'Pitch Analysis' (vol. 39, 1982), 'Prosodic Cues for Segments' (vol. 43, 1986), 'Articulatory Organization: From Phonology to Speech Signals' (vol. 45, 1988), 'On the Relation between Phonetics and Phonology' (vol. 48, 1991), 'Articulatory Phonology' (vol. 49, 1992), 'The Speaker, the Listener, and the Child' (Festschrift on the Occasion of Björn Lindblom's 60th Birthday; vol. 51, 1994), 'Emergence and Adaptation Studies in Speech Communication and Language Development' (Dedicated to Björn Lindblom on his 65th Birthday; vol. 57, 2000), and 'Progress in Experimental Phonology - From Communicative Function to Phonetic Substance and Vice Versa' (vol. 62, 2005).

The editors have shaped Phonetica according to a firm epistemological stand, but it has remained an open forum for alternative views. As scientific thinking has been advancing since 1932, Phonetica has mirrored this progress, and it will continue to be at the forefront of new developments. 


\section{Phonetica's Scientific Perspective - From Sound to Communicative Function}

In the conception of language functions in the 1930s and of normative linguistic units of Zwirner's phonometry, word differentiation played a central role, as it always has. Therefore, distinctive sound features separating phonemic categories have been a focus of research in the various phonetics - phonology paradigms. The phoneme is a very useful heuristic concept in citation-form word phonology, especially in dialect and language fieldwork to establish the sound system and its phonetic manifestation for the representation of words. This also helps in devising economical alphabetic writing systems for unwritten languages and for phonetic transcription. But phonetic research has moved on to the phonology of words at the phrase level, where the phonemic segment can be no more than a canonical reference for grouping variants of the 'same' word to classes for data access. The sound reductions and reinforcements that occur in utterance contexts call for a transgression of the distinctive feature as well as the phonemic segment. We need to take both fine phonetic detail into account, and proceed to long sound components above the segment in production and in perception. This means that initial heuristic segmental phonemic categories imported from phonology need to be adjusted by auditory phonetic description as well as by related experimental measurement in laboratory analysis: in this sense, phonology becomes part of the laboratory output, rather than being its input for phonetic substantiation at, for instance, the isolated word level.

Another aspect that has gained increasing attention and will continue to do so is the central role of function in the investigation of speech communication. This was the central issue of de Groot's 1932 memorandum. More recent developments of phonetic science have lost sight of this core requirement by restricting themselves to autonomous signal-based phonology. But the demand to relate speech phenomena to functional categories is voiced again very strongly, and is also captured in the name, and no doubt in the spirit, of the Project 'Sound to Sense' within the Marie Curie Research Training Networks. The 2005 thematic issue of Phonetica put communicative function in focus, and also argued for an incorporation of all communicative functions, including, but going beyond, such linguistic ones as word differentiation, focus, sentence mode. We need to transcend traditional linguistic categories, particularly in prosody research, and extend the communicative network to expressive functions, such as 'emphasis', to functions of 'interaction with the addressee', and to functions of 'argumentation', such as 'concluding', 'opening', 'contrasting argument', i.e. Bühler's 'Ausdrucksfunktion', 'Appellfunktion', and 'Darstellungsfunktion' related to the speaker, the hearer, and the factual world, respectively [Bühler, 1934]. This does not throw out the existing categories but relegates them to certain investigations, such as the phoneme to word phonology, fieldwork in unwritten languages, and research into motor control. With this communicative functional perspective phonetics becomes very interesting for researchers in the social sciences - social psychology, sociology, anthropology, psychiatry, neurology. Questions of communicative typologies and universals will follow naturally, e.g. how are different categories of 'emphasis' or of 'argumentation' structure realized across the languages of the world?

A third aspect that needs reconsideration in speech science, in connection with its communicative orientation, is data acquisition. Zwirner made a strong plea for the use of spontaneous speech, and although he focussed on word differentiation, there are plenty of theoretical references in his book that show how clearly he saw the essentials 
of speech communication. Today large semi-spontaneous acoustic speech corpora are available, e.g. MAP Task corpora in various languages, the Switchboard Corpus of Recorded Telephone Conversations, the Kiel Corpus of Spontaneous Speech. But often the processing stopped after the digitization, and even if the data are annotated the annotation is not based on the systematic application of a uniform system of categories at the segmental, prosodic and linguistic levels, so that access for communicative analysis becomes at best difficult. But this is not the only problem in data acquisition that needs a lot more attention. Far more fundamental is a reflection on data collection procedures themselves, more particularly for systematic experiments. To study communicative aspects of sound we need utterances in situational context, and depending on the research question also in dialogue. Logatomes in metalinguistic sentence frames have a certain value in phoneme - signal studies, but even there it is limited because the generalization of the results to speaking situations in context is highly problematic since the sentence construction highlights the logatome and creates a prosodic frame that has an influence on the production parameters under investigation. Isolated sentences, frequently with a high degree of semantic implausibility, are standard practice in prosody research, but they will not do under a communicative perspective. This means that we need to reflect on a methodology of data acquisition that combines spontaneous corpora from natural interaction with systematic data collection for experimental analysis, based on various types of contextualization and dialogue simulation, controlled by the research question at hand.

Phonetica opens its pages to all discussions of theoretical as well as methodological issues and of new data from empirical investigations; it particularly welcomes any contributions on those hot topics of 'fine phonetic detail' beyond the segment and the phoneme, of 'communicative functions', including typologies and universals, and of the 'methodology of data acquisition', and any other new theme of great prospect. On behalf of the publishing house S. Karger, the editorial staff, and the many contributors over the years I wish our birthday child all the best for the future, as a platform for interesting, lively, progressive scientific interchange. May it prosper as a mouthpiece for Communicative Phonetic Science!

Klaus J. Kohler, Editor

August 2007

\section{References}

Bühler, K.: Sprachtheorie (Fischer, Jena 1934).

de Groot, A.W.: Proposition 2: Explanatory memorandum; in Actes du Premier Congrès International de Linguistes, pp. 6-9 (Sijthoff's Uitgeversmaatschappij, Leiden 1928).

Fischer-Jørgensen, E.: Some aspects of the 'Phonetic Sciences', past and present; in van den Broecke, Proc. 10th Int. Congr. Phonet. Sci., pp. 3-11 (Foris, Dordrecht 1984).

Pierrehumbert, J.; Beckman, M.E.; Ladd, D.R.: Conceptual foundations of phonology as a laboratory science; in Burton-Roberts, Carr, Docherty, Phonological knowledge: conceptual and empirical issues, pp. 273-303 (Oxford University Press, Oxford 2000).

Trubetzkoy, N.: Charakter und Methode der systematischen phonologischen Darstellung einer gegebenen Sprache. Proc. Int. Congr. Phonet. Sci., Amsterdam 1932. Archs néerl. Phon. exp. VIII-IX: 109-115 (1933).

Zwirner, E.: Quantität, Lautdauerschätzung und Lautkurvenmessung (Theorie und Material). Proc. Int. Congr. Phonet. Sci., Amsterdam 1932. Archs néerl. Phon. exp. VIII-IX: 236-246 (1933).

Zwirner, E.; Zwirner, K.: Grundfragen der Phonometrie (1936); 2nd ed. (Karger, Basel 1966).

Zwirner, E.; Zwirner, K.: Grundfragen der phonometrischen Linguistik; 3rd ed. (Karger, Basel 1982). 